\section{PROTECTION AGAINST INJURY DURING ISCHEMIA AND REPERFUSION BY ACADESINE DERIVATIVES GP-1-468 AND GP-1-668}

\section{Studies in the transplanted rat heart}

Background. Acadesine (AICAr: 5-amino-4-imidazole carboxamide riboside) has been shown to afford sustained protection against injury during ischemia and reperfusion. The present studies used the heterotopically transplanted rat heart to assess the protective properties of two new acadesine analogs: GP-1-468 and GP-1-668. Methods and results. Hearts were excised, arrested with a 2 -minute infusion of cardioplegic solution, and subjected to 4 hours of global ischemia $\left(20^{\circ} \mathrm{C}\right)$ with cardioplegic reinfusion for 2 minutes every 30 minutes. The hearts were then transplanted ( 1 hour of additional ischemia) into the abdomens of recipient rats and reperfused in situ for 30 minutes or 24 hours. The hearts were then excised, perfused aerobically for $\mathbf{2 0}$ minutes, and contractile function was assessed. GP-1-468 or GP-1-668 was administered to donor rats (20 mg/kg intravenously, 30 minutes before excision). They were also added to the cardioplegic solution (10 $\mu \mathrm{mol} / \mathrm{L}$ for GP-1-468, $5 \mu \mathrm{mol} / \mathrm{L}$ for $\mathrm{GP}-1-343$, the active metabolite of GP-1-668) and were also given to recipient rats (20 $\mathrm{mg} / \mathrm{kg}$ intravenously, 30 minutes before transplantation, so that the drugs were present during reperfusion). Nine groups of hearts were studied. Three groups of studies were carried out $(n=24$ transplants for each group). The first group of hearts was reperfused for 30 minutes, the second group was reperfused for 24 hours, and the third group was transplanted but not reperfused; instead, they were frozen at the end of 5 hours of ischemia and taken for metabolite analysis. Within each group were three subgroups ( $n=8$ per group) receiving GP-1-468, GP-1-668, or saline solution. In the 30-minute reperfusion group the recoveries of left ventricular developed pressure were $88 \pm 4,87 \pm 7$, and $50 \pm 9 \mathrm{~mm} \mathrm{Hg}$, respectively ( $p<0.05$ versus saline-treated controls); left ventricular volumes (recorded at $12 \mathrm{~mm} \mathrm{Hg}$ ) were $112 \pm 20,132 \pm 28$, and $41 \pm 9 \mu \mathrm{l}$, respectively ( $p<0.05$ versus saline-treated controls), and coronary flows were $13.1 \pm 0.7,13.4 \pm 1.0$, and $9.9 \pm 0.5 \mathrm{ml} / \mathrm{min}$, respectively $(p<0.05$ versus saline-treated controls). In addition to improving functional recovery, the two analogs increased the tissue content of adenosine at the end of the ischemic period $(5.4 \pm 0.6$ and $7.3 \pm 0.5 \mu \mathrm{mol} / \mathrm{gm}$ dry weight, respectively, versus $2.7 \pm$ $0.4 \mu \mathrm{mol} / \mathrm{gm}$ dry weight in the saline-treated controls; $p<0.05$ ); however, they did not influence adenosine triphosphate or its catabolites. In the 24-hour reperfusion group the corresponding values were $77 \pm 6$ and $88 \pm 6$ versus $35 \pm 4 \mathrm{~mm} \mathrm{Hg}$ for left ventricular developed pressure $(p<0.05), 111 \pm 9$ and $121 \pm 11$ versus $41 \pm 8 \mu$ l for left ventricular volume $(p<0.05)$, and $13.7 \pm$ 0.7 and $13.0 \pm 0.6$ versus $11.7 \pm 0.7 \mathrm{ml} / \mathrm{min}$ for coronary flow (no significant difference). Thus both analogs afforded an early and comparable degree of

Manuel Galiñanes, $\mathrm{MD}, \mathrm{PhD},{ }^{\mathrm{a}}$ Xiaolin Zhai, $\mathrm{MD},{ }^{\mathrm{a}}$ David Bullough, $\mathrm{PhD},{ }^{\mathrm{b}}$

Kevin M. Mullane, $\mathrm{PhD},{ }^{\mathrm{b}}$ and David J. Hearse, $\mathrm{PhD}, \mathrm{DSc},{ }^{\mathrm{a}}$

London, United Kingdom, and San Diego, Calif.
From Cardiovascular Research, The Rayne Institute, St. Thomas' Hospital, London, United Kingdom, ${ }^{\mathrm{a}}$ and Gensia Pharmaceuticals, Inc., San Diego, Calif. ${ }^{\text {b }}$

Received for publication August 12, 1994.

Accepted for publication Dec. 29, 1994.
Address for reprints: Manuel Galiñanes, MD, $\mathrm{PhD}$, Cardiovascular Research, The Rayne Institute, St. Thomas' Hospital, London SE1 7EH, United Kingdom.

J Thorac CARDIOvasC Surg 1995;110:752-61

Copyright (C) 1995 by Mosby-Year Book, Inc.

$0022-5223 / 95 \$ 5.00+0 \quad \mathbf{1 2} / \mathbf{1} / \mathbf{6 3 1 8 5}$ 
protection of contractile function that was sustained even after 24 hours of reperfusion. Conclusions. Both GP-1-468 and GP-1-668 increase the rate and extent of early postischemic recovery, and this protection is sustained for at least 24 hours. These beneficial actions were associated with an increase of the tissue content of adenosine during ischemia, but they appeared to be independent of the status of the high-energy metabolism. (J THORAC CARDIOVASC SURG 1995;110:752-61)

A growing body of evidence indicates that acadesine (AICAr: 5-amino-4-imidazole carboxamide riboside) can exert a variety of beneficial effects on the cardiovascular system. It is thought to increase regional blood flow by increasing local adenosine concentration. ${ }^{1,2}$ It can inhibit neutrophil activation, ${ }^{3}$ suppress platelet activation and intracoronary thrombosis, ${ }^{4,5}$ prevent oxidant-induced injury, ${ }^{6}$ inhibit glycolysis, ${ }^{7}$ and potentiate the protective mechanisms induced by myocardial preconditioning. ${ }^{8}$ Using the isolated crystalloid-perfused rat heart ${ }^{9}$ and the blood-perfused transplanted rat heart, ${ }^{10}$ we have reported previously that acadesine increases the myocardial adenine nucleotide and adenosine contents at the end of ischemia and improves the postischemic recovery of contractile function. Furthermore, we were able to demonstrate that acadesine could afford a sustained protection of cardiac contractile function for at least the first 24 hours of reperfusion, which suggests that it may act by reducing necrosis rather than simply accelerating recovery from stunning. In other models of myocardial ischemia-reperfusion injury, the benefits of acadesine are accompanied by elevated adenosine levels. ${ }^{1,2}$ However, the benefit can be attenuated if adenosine formation is suppressed or adenosine receptor blocked. ${ }^{11,12}$

Recently, two acadesine analogs, GP-1-468 (5amino-5-deoxy- $\beta$-D-ribofuranosylimidazole $4 N$-[(4chlorophenyl)methyl]carboxamide) and GP-1-668 (the soluble monophosphate of the active species GP-1-343; 5-amino-1- $\beta$-D-ribofuranosylimidazole $4 N$ [(4-nitrophenyl)methyl]carboxamide), have been synthesized (Fig. 1). These analogs have a greater potency than acadesine in terms of their ability to augment extracellular adenosine levels during adenosine triphosphate breakdown (such as occurs in ischemia), and these agents have been suggested to possess antiischemic properties that are mediated by adenosine. ${ }^{13,14}$ However, these two compounds differ with respect to other pharmacologic properties. Only GP-1-468 is a potent inhibitor of lipid peroxidation by virtue of its chemical structure, ${ }^{14}$ whereas GP-1-668 inhibits intravascular thrombosis in vivo, ${ }^{15,16}$ an effect not shared by GP-1-468.

With these different pharmacologic profiles in mind, we designed the present study with two aims. First, we sought to compare the protective properties of the two acadesine analogs in relation to their ability to reduce injury occurring during global ischemia and reperfusion using the same model in which acadesine was previously shown to be effective, even after 24 hours of reperfusion. Second, we investigated whether these analogs exert any effect on the tissue content of adenosine and high-energy phosphates at the end of the ischemic period.

\section{Materials and methods}

Animals. Male homozygous Lewis rats, weighing 200 to $250 \mathrm{gm}$, were used. All animals received humane care in compliance with the "Principles of Laboratory Animal Care" formulated by the National Society for Medical Research and the "Guide for the Care and Use of Laboratory Animals" prepared by the National Academy of Sciences and published by the National Institutes of Health (NIH No. 86-23, revised 1985).

Surgical procedures

Excision and storage of hearts. Each rat was anesthetized with pentobarbital $(60 \mathrm{mg} / \mathrm{kg}$ intraperitoneally) and the lungs were mechanically ventilated through a tracheostomy at a rate of 55 strokes/min with a ventilation pressure of 12 to $14 \mathrm{~mm} \mathrm{Hg}$. The chest was opened and the venae cavae and pulmonary veins were isolated; heparin was administered (1000 IU $/ \mathrm{kg}$ intravenously). The venae cavae and pulmonary veins were then ligated and the heart was excised and placed in cold $\left(4^{\circ} \mathrm{C}\right)$ saline solution. The aorta was rapidly cannulated and St. Thomas' Hospital cardioplegic solution (containing, in millimoles per liter: $\mathrm{NaCl} 110.0 \mathrm{KCl} 16.0, \mathrm{MgCl}_{2} 16.0, \mathrm{CaCl}_{2}$ 1.2 , and $\mathrm{NaHCO}_{3} 10.0$ at $\mathrm{pH} 7.8$ ) at $20^{\circ} \mathrm{C}$ was infused for 2 minutes at a constant pressure of $45 \mathrm{~mm} \mathrm{Hg}$. Each heart was then stored for 4 hours at $20^{\circ} \mathrm{C}$; during this time it was immersed in the same cardioplegic solution and reinfused with the solution for 2 minutes every 30 minutes. This protocol, which was identical to the one used in our previous study with acadesine, ${ }^{10}$ was chosen to investigate and to compare the potential benefit of the acadesine analogs GP-1-468 and GP-1-668 in the presence of severe functional impairment.

Transplantation procedure. The abdomen of an anesthetized recipient rat was opened through a midline incision and the abdominal aorta and inferior vena cava were 
<smiles>NC(=O)c1ncn([C@@H]2O[C@H](CO)[C@@H](O)[C@H]2O)c1N</smiles>

Acadesine<smiles>NC[C@H]1O[C@@H](n2cnc(C(=O)NCc3ccc(Cl)cc3)c2N)[C@H](O)[C@@H]1O</smiles>

GP-1-468<smiles>Nc1c(C(=O)NCc2ccc([N+](=O)[O-])cc2)ncn1[C@@H]1O[C@H](COP(=O)(O)O)[C@@H](O)[C@H]1O</smiles>

GP-1-668

Fig. 1. Chemical structure of acadesine and its analogs GP-1-468 and GP-1-668.

exposed. The donor heart (which had been stored for 4 hours) was removed from the hypothermic chamber and, the aorta and pulmonary artery were anastomosed (end to side) to the abdominal aorta and inferior vena cava of the recipient rat with 10-0 Ethicon sutures (Ethicon, Inc., Somerville, N.J.). The heart was maintained at $18^{\circ}$ to $22^{\circ} \mathrm{C}$ during the implantation period; this was achieved by wrapping it in a swab that was regularly irrigated with cold $\left(6^{\circ}\right.$ to $\left.10^{\circ} \mathrm{C}\right)$ saline solution. The duration of the implantation period was standardized at 60 minutes for all studies to minimize variability between experiments. Hearts were then reperfused with blood, in situ, for 30 minutes or 24 hours. When the hearts were reperfused for 24 hours, the abdominal wall of the recipient rats was closed in two layers and the animals were allowed to recover in an unrestrained state with free access to food and water.

Assessment of cardiac function after transplantation and reperfusion. Thirty minutes or 24 hours after implantation and reperfusion of the transplanted hearts, each recipient rat was again anesthetized, the right femoral vein was exposed, and heparin was administered (1000 $\mathrm{IU} / \mathrm{kg}$ intravenously). The abdomen was reopened and the transplanted heart was excised and placed in cold $\left(4^{\circ} \mathrm{C}\right)$ saline solution. The aorta was rapidly cannulated and each heart perfused aerobically with crystalloid perfusion fluid $^{17}$ (containing, in millimoles per liter: glucose 11.1, $\mathrm{NaCl} 118.5, \mathrm{KCl} 4.8, \mathrm{MgSO}_{4} 1.2, \mathrm{KH}_{2} \mathrm{PO}_{4} 1.2, \mathrm{NaHCO}_{3}$ $25.0, \mathrm{CaCl}_{2} 1.4$ at $\mathrm{pH} 7.4$ when gassed with $95 \% \mathrm{O}_{2}$ plus $\left.5 \% \mathrm{CO}_{2}\right)$ at a constant pressure $(75 \mathrm{~mm} \mathrm{Hg})$ in the Langendorff mode ${ }^{18}$ at $37^{\circ} \mathrm{C}$ for 20 minutes. Before use, perfusion and cardioplegic solutions were filtered through a $5 \mu \mathrm{m}$ pore filter. A silver pacing wire was connected to the right atrium, a second pacing wire was attached to the aortic cannula, and hearts were paced at a fixed rate of 320 beats $/ \mathrm{min}$. After 20 minutes of reperfusion, coronary flow was measured and function curves for left ventricular developed pressure (LVDP) were constructed with an intraventricular balloon by progressively increasing its volume to achieve end-diastolic pressures (LVEDP) of 0 , $4,8,12,16$, and $20 \mathrm{~mm} \mathrm{Hg}$. In this manner, contractile function was assessed by subjecting hearts to an identical ventricular load and avoiding overdistention of the left ventricle (LV) that may have arised from fixed increments of predetermined balloon volumes.

Study groups. In all, nine groups of hearts $(n=8$ per group) were studied. These were divided into three groups, each with three subgroups. In one group, the hearts were transplanted but were not reperfused; instead, they were freeze clamped at the end of 5 hours of ischemia (4 hours of storage plus 1 hour of transplantation) and were then taken for metabolite analysis. In the second group, hearts were transplanted and then reperfused for 30 minutes. In the third group, hearts were reperfused for 24 hours. Within each group there were three subgroups. One subgroup (controls) received saline solution. One subgroup received GP-1-468 that was given $(20 \mathrm{mg} / \mathrm{kg}$, intravenously) to the donor rat 30 minutes before the excision of the heart. The drug was also included as an additive $(10 \mu \mathrm{mol} / 1)$ in the cardioplegic solution that was infused before and during ischemia, and it was also given $(20 \mathrm{mg} / \mathrm{kg}$, intravenously) to the recipient rat 30 minutes before implantation in order that it be present during reperfusion. The third subgroup received GP-1-668. Again, it was given $(20 \mathrm{mg} / \mathrm{kg}$, intravenously) 30 minutes before the excision of the heart, it was included as an additive to the cardioplegic solution (however, GP-1-343, $5 \mu \mathrm{mol} / 1$, the active metabolite of GP-1-668, was used in place of GP-1-668), and the drug was given $(20 \mathrm{mg} / \mathrm{kg}$, intravenously) to the recipient rat 30 minutes before implantation, so as to be present during reperfusion of the transplanted heart.

For comparative purposes, eight hearts were not subjected to ischemia but were perfused aerobically with crystalloid solution for 20 minutes and then used for the measurement of control aerobic cardiac function and metabolism.

Analysis of high-energy phosphates and their catabolites. Frozen hearts were lyophilized and homogenized in $3 \mathrm{ml}$ of perchloric acid $(0.6 \mathrm{~mol} / \mathrm{L})$ at $4^{\circ} \mathrm{C}$. Each homogenate was then centrifuged at $2000 \mathrm{~g}$ for 10 minutes at $4^{\circ} \mathrm{C}$. A portion $(0.6 \mathrm{ml})$ of the supernatant was then neutralized by the addition of $0.045 \mathrm{ml}$ potassium carbonate $(5 \mathrm{~mol} / \mathrm{L})$; the mixture was left on ice for 5 minutes and then centrifuged as previously. The supernatant was passed through a $0.45 \mu \mathrm{m}$ mesh nylon filter and stored at $-20^{\circ} \mathrm{C}$ before high-performance liquid chromatography analysis. ${ }^{19}$ Nucleotides and their metabolites were analyzed with a Waters high-performance liquid chromatography system (Waters Corp., Rochester, Minn.) comprising two 510 pumps, a $1 \mathrm{ml}$ static mixing chamber, a WISP 712 automated sample injector with refrigeration unit (Waters HPLC System, Waters Corp., S. San Francisco, Calif.), and a 441 detector set at $254 \mathrm{~nm}$. The following 
intermediates were measured: adenosine triphosphate (ATP), adenosine diphosphate (ADP), adenosine monophosphate (AMP), inosine monophosphate (IMP), adenosine, inosine, and hypoxanthine. The values obtained were used to calculate the following indexes of myocardial energy status:

Adenylate pool $=[\mathrm{ATP}+\mathrm{ADP}+\mathrm{AMP}]$

Energy charge potential $=$

$$
[0.5 \mathrm{ADP}+\mathrm{ATP}] /[\mathrm{ATP}+\mathrm{ADP}+\mathrm{AMP}]
$$

The limits of detection for quantification of spectrally matched metabolites in $50 \mu \mathrm{l}$ aliquots taken from the $3 \cdot \mathrm{ml}$ samples were $5 \mathrm{nmol} / \mathrm{gm}$ tissue for the nucleotides and 10 nmol/gm for the nucleosides.

Exclusion criteria. Experiments in which the support animal died as a consequence of bleeding and hearts in which intraventricular thrombosis developed were excluded.

Expression of results and statistical analyses. LVDP was calculated as the difference between peak systolic pressure and LVEDP. Coronary flow (milliliters per minute) was measured by timed collection of coronary effluent. Tissue metabolite contents were expressed as micromoles per gram dry weight. All results were expressed as means \pm standard error of the means. Analysis of variance was used for comparison of more than two means; when a significant $F$ value was obtained, comparisons between the different groups were carried out by means of Tukey's test. A difference was considered statistically significant when $p<0.05$.

\section{Results}

From the 80 hearts initially entered into the study, only five hearts were excluded: two because of arterial bleeding after transplantation (in the saline solution and GP-1-668 groups) and three because of formation of intraventricular thromboses after 24 hours of reperfusion (two in the GP-1-468 group and one in the saline solution group). The excluded hearts were replaced according to the randomization protocol.

Metabolic studies after 5 hours of hypothermic ischemia. The results in Fig. 2 show that in the saline-treated controls, the tissue content of adenosine at the end of 5 hours of hypothermic ischemia increased from $0.1 \pm 0.01 \mu \mathrm{mol} / \mathrm{gm}$ dry weight (the value in aerobically perfused hearts) to $2.8 \pm 0.4$ $\mu \mathrm{mol} / \mathrm{gm}$ dry weight $(p<0.05)$. By contrast, hearts treated with GP-1-468 had an adenosine content that was twice that observed in saline-treated controls. Hearts treated with GP-1-668 had an even higher value $(7.3 \pm 0.5 \mu \mathrm{mol} / \mathrm{gm}$ dry weight; $p<$ 0.05 versus saline-treated controls and the GP-1468-treated group). The greater adenosine content in the GP-1-468- and GP-1-668-treated hearts was

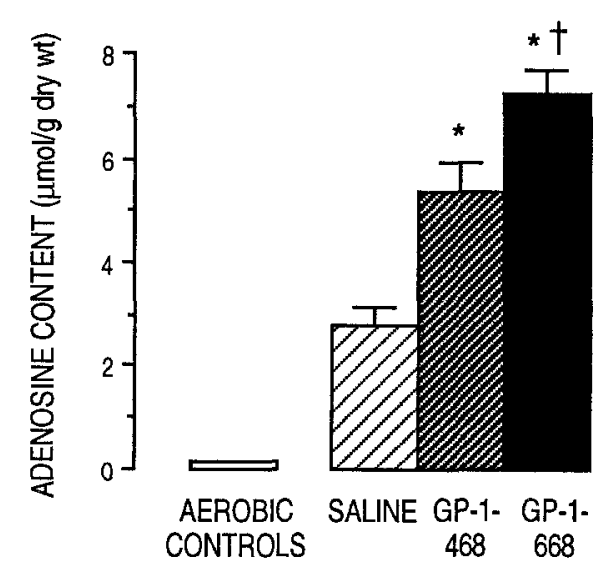

Fig. 2. Tissue adenosine content at the end of 5 hours of ischemia in saline-treated hearts and hearts receiving GP-1-468 or GP-1-668 ( $n=8$ per group). The bars indicate the standard error of the mean. ${ }^{*} p<0.05$ when compared with saline-treated controls; $\dagger p<0.05$ when compared with the GP-1-468-treated group.

reflected by a decreased hypoxanthine content (Table I). The content of adenosine triphosphate and its catabolites, together with the adenylate charge potential, were substantially reduced by ischemia in the saline-treated controls. This decrease was not significantly affected by the treatment with either of the two acadesine analogs (Table I).

Functional studies after $\mathbf{3 0}$ minutes of reperfusion

Contractile function. The results in Fig. 3 show that, in comparison with nonischemic aerobic controls, saline-treated hearts subjected to 5 hours of hypothermic ischemia had substantial injury and a deterioration of systolic (Fig. 3, A) and diastolic (Fig. 3, $B$ ) function. In contrast, the administration of either GP-1-468 or GP-1-668 afforded comparable, substantial, and significant improvements in postischemic cardiac function over the entire range of LVEDP and LV volumes. Taking an LVEDP of $12 \mathrm{~mm} \mathrm{Hg}$ as an example, the recovery of both LVDP and the LV volume increased from $50 \pm 9$ $\mathrm{mm} \mathrm{Hg}$ and $41 \pm 9 \mu \mathrm{l}$ in the saline-treated controls to $88 \pm 4 \mathrm{~mm} \mathrm{Hg}$ and $112 \pm 20 \mu \mathrm{l}$ in the GP-1-468treated hearts and to $87 \pm 7 \mathrm{~mm} \mathrm{Hg}$ and $132 \pm 28$ $\mu l$ in the GP-1-668-treated hearts $(p<0.05$ in all instances).

Coronary flow. The postischemic recovery of coronary flow (Fig. $4, A$ ) in saline-treated controls was significantly decreased to $78 \%$ of the aerobic control value $(9.9 \pm 0.5$ versus $12.6 \pm 0.4 \mathrm{ml} / \mathrm{min} ; p<0.05)$. However, coronary flow completely recovered in 
Table I. Tissue metabolite content in aerobic control hearts and hearts at the end of 5 hours of ischemia (4 hours of hypothermic storage plus 1 hour of transplantation) that were treated with saline solution or the acadesine analogs GP-1-468 and GP-1-668 (see text for details)

\begin{tabular}{|c|c|c|c|c|c|c|c|c|c|}
\hline \multirow[b]{2}{*}{ Group } & \multirow[b]{2}{*}{$n$} & \multicolumn{7}{|c|}{ Tissue content ( $\mu$ mol/gm dry wt) } & \multirow[b]{2}{*}{$A C P$} \\
\hline & & $A T P$ & $A D P$ & $A M P$ & $I M P$ & INO & $H Y P$ & $A P$ & \\
\hline Aerobic controls & 8 & $23.3 \pm 0.2$ & $3.6 \pm 0.1$ & $4.3 \pm 0.2$ & ND & $0.05 \pm 0.01$ & ND & $31.2 \pm 0.5$ & $0.81 \pm 0.01$ \\
\hline Saline solution & 8 & $1.0 \pm 0.2$ & $1.6 \pm 0.2$ & $9.7 \pm 0.6$ & $4.4 \pm 0.4$ & $7.73 \pm 1.11$ & $2.81 \pm 0.33$ & $12.3 \pm 0.9$ & $0.14 \pm 0.02$ \\
\hline GP-1-468 & 8 & $1.4 \pm 0.2$ & $2.2 \pm 0.1$ & $10.7 \pm 0.5$ & $4.3 \pm 4.4$ & $7.78 \pm 0.58$ & $1.89 \pm 0.21^{*}$ & $14.3 \pm 0.7$ & $0.17 \pm 0.01$ \\
\hline GP-1-668 & 8 & $1.4 \pm 0.2$ & $1.9 \pm 0.1$ & $10.9 \pm 0.6$ & $4.5 \pm 0.3$ & $6.80 \pm 0.45$ & $1.38 \pm 0.17^{*}$ & $14.2 \pm 0.6$ & $0.17 \pm 0.02$ \\
\hline
\end{tabular}

$A T P$, Adenosine triphosphate; $A D P$, adenosine diphosphate; $A M P$, adenosine monophosphate; $I M P$, inosine monophosphate; INO, inosine; $H Y P$, hypoxanthine; $A P$, adenylate pool; $A C P$, adenylate charge potential; $N D$, not detected.

${ }^{*} p<0.05$ versus saline-treated groups.

hearts treated with either GP-1-468 or GP-1-668 $(13.1 \pm 0.7$ and $13.4 \pm 1.0 \mathrm{ml} / \mathrm{min}$, respectively; $p=$ no significant difference versus aerobic controls).

Metabolic and functional studies after 24 hours of reperfusion

Contractile function. The results in Fig. 5 show that, after 24 hours of reperfusion, hearts in the saline-treated group had a sustained deterioration of contractile function that was even more severe than that observed after 30 minutes of reperfusion. Thus, at an LVEDP of $12 \mathrm{~mm} \mathrm{Hg}$, LVDP was $35 \pm$ $4 \mathrm{~mm} \mathrm{Hg}$ compared with $50 \pm 9 \mathrm{~mm} \mathrm{Hg}$ after 30 minutes of reperfusion and $138 \pm 8 \mathrm{~mm} \mathrm{Hg}$ in the aerobic controls. Again, however, the administration of either GP-1-468 or GP-1-668 resulted in a sustained and significant improvement in the recovery of systolic and diastolic function at all LVEDPs. Taking an LVEDP of $12 \mathrm{~mm} \mathrm{Hg}$ as an example, the recoveries of LVDP and LV volume were increased from $35 \pm 4 \mathrm{~mm} \mathrm{Hg}$ and $41 \pm 8 \mu \mathrm{l}$ in the saline-treated group to $77 \pm 6 \mathrm{~mm} \mathrm{Hg}$ and $111 \pm 9$ $\mu 1$ in the GP-1-468-treated group and to $84 \pm 6 \mathrm{~mm}$ $\mathrm{Hg}$ and $121 \pm 11 \mu \mathrm{l}$ in the GP-1-668-treated group ( $p<0.05$ in all instances). In contrast with the saline-treated group, there was no significant deterioration in function between 30 minutes and 24 hours of reperfusion in hearts treated with GP-1-468 or GP-1-668.

Coronary flow. After 24 hours of reperfusion, the mean coronary flow (Fig. 4, $B$ ) in the saline-treated group recovered to a level similar to that observed in aerobically perfused hearts $(11.7 \pm 0.7$ versus $12.6 \pm$ $0.4 \mathrm{ml} / \mathrm{min}$, respectively). The values for coronary flow in the hearts treated with GP-1-468 (13.7 \pm 0.7 $\mathrm{ml} / \mathrm{min})$ and those treated with GP-1-668 (13.0 \pm $0.6 \mathrm{ml} / \mathrm{min}$ ) were also similar to the values in the saline-treated hearts and in the nonischemic controls.

\section{Discussion}

The present studies with the heterotopically transplanted rat heart have shown that two analogs of acadesine can confer considerable protection against injury during ischemia and reperfusion. This protection (measured on the basis of an ex vivo assessment of cardiac function) is apparent as soon as 30 minutes after the onset of reperfusion. However, this protection is sustained, and indeed enhanced, after 24 hours of in vivo reperfusion, which suggests that the protective effect of the drugs is more likely to involve a reduction in the extent of necrosis rather than an acceleration of the recovery from stunning.

A number of additional observations can be made that may shed some light on the mechanism by which protection is achieved. First, the protection afforded by GP-1-468 is almost identical to that provided by GP-1-668. This similarity would suggest that any differences in secondary pharmacologic properties between these compounds are unlikely to be important determinants of protection. Second, comparison of the results of the present study with those of our previous study ${ }^{10}$ (which used an identical model and protocol) reveals that the quantitative and qualitative characteristics of the protection of contractile function are virtually identical to those observed with the parent compound, acadesine. Again, this would suggest that the secondary pharmacologic properties of these molecules may be relatively unimportant in influencing functional end points of injury.

Although GP-1-468, GP-1-668, and acadesine may act in a similar manner in terms of influencing postischemic recoveries of LVDP, LV volume, and coronary flow, we cannot rule out the possibility that differences in their secondary pharmacologic properties (e.g., in relation to antithrombotic and anti- 

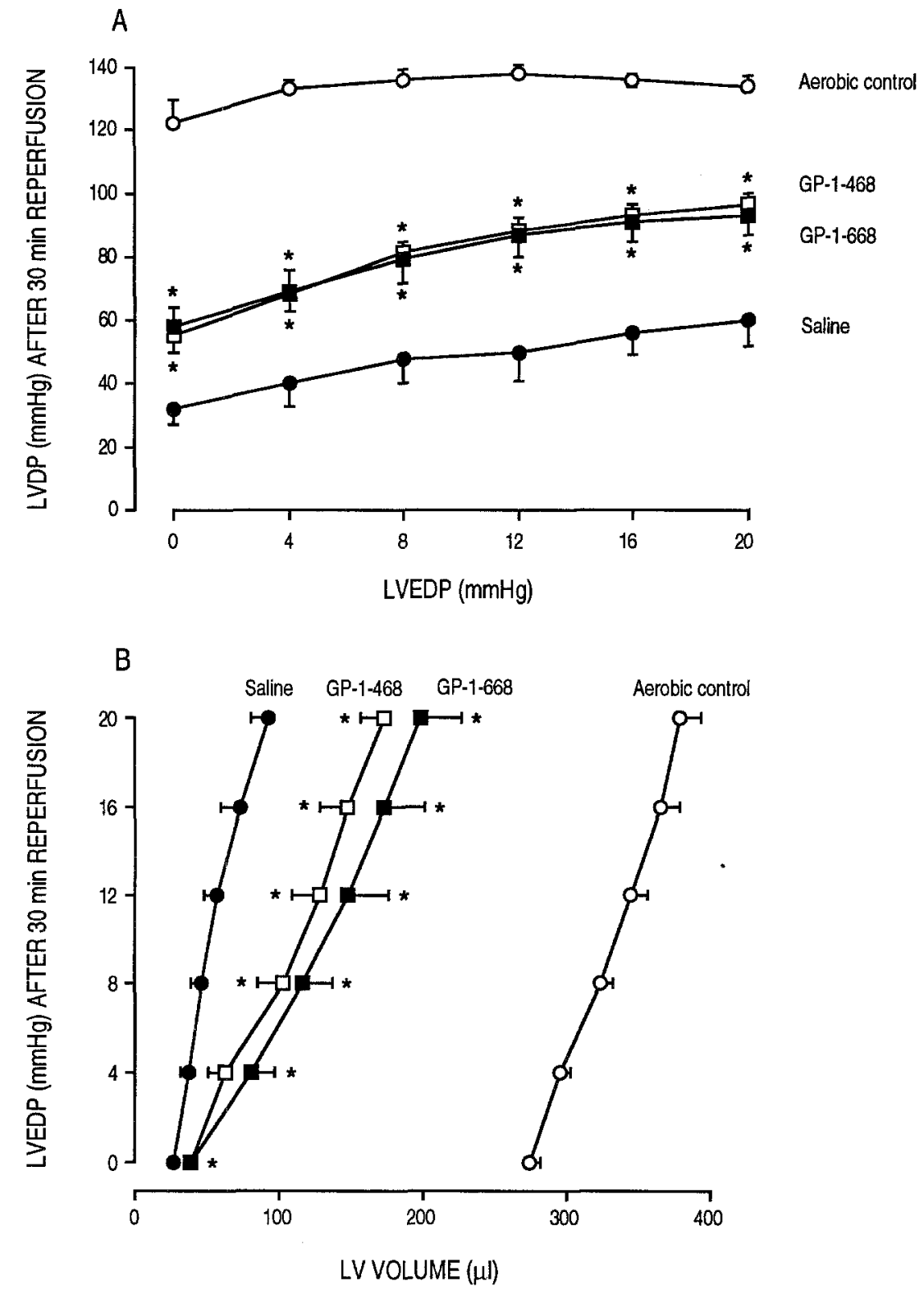

Fig. 3. Systolic (A) and diastolic (B) contractile function curves obtained in aerobic, nonischemic control hearts and in hearts reperfused for 30 minutes after 5 hours of ischemia, each treated with saline solution, GP-1-468, or GP-1-668. LVEDP was increased stepwise from 0 to 4, 8, 12, 16, and $20 \mathrm{~mm} \mathrm{Hg}$ ( $n=8$ per group). The bars indicate the standard error of the mean. * $p<0.05$ when compared with saline-treated hearts.

lipid peroxidative properties) may beneficially affect end points not measured in the present studies.

Chemical structure and adenosine-regulating activity of GP-1-468 and GP-1-668. Acadesine, the parent molecule, is effective in reducing myocardial injury induced by ischemia and reperfusion in a variety of settings in different species., ${ }^{1,-11}$ This activity is prevented if endogenous adenosine is suppressed or adenosine receptors are blocked, which indicates mediation by local adenosine..$^{11,12}$ Moreover, recent studies indicate that acadesine attenuates myocardial injury in patients undergoing coronary artery bypass graft operations. ${ }^{20}$ GP-1-468 and GP-1-668 are two of a series of structural analogs of acadesine (see Fig. 1), synthesized to improve on the ability of acadesine to augment extracellular adenosine during periods of stress 
A

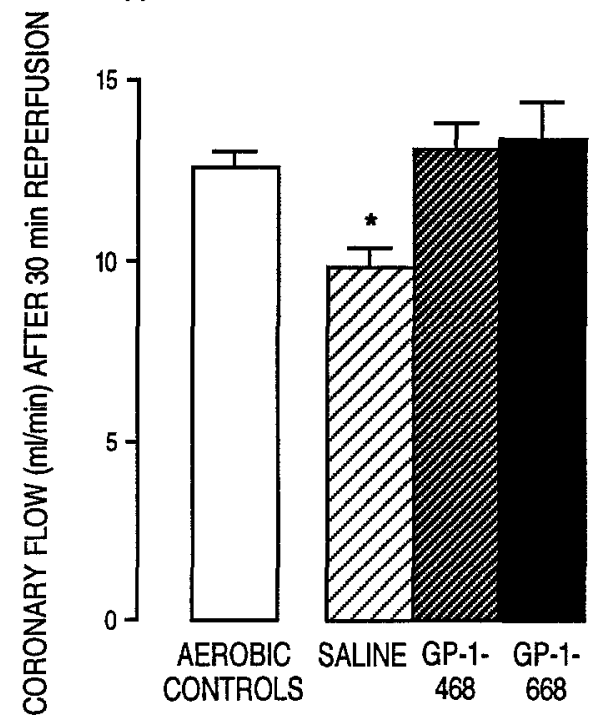

B

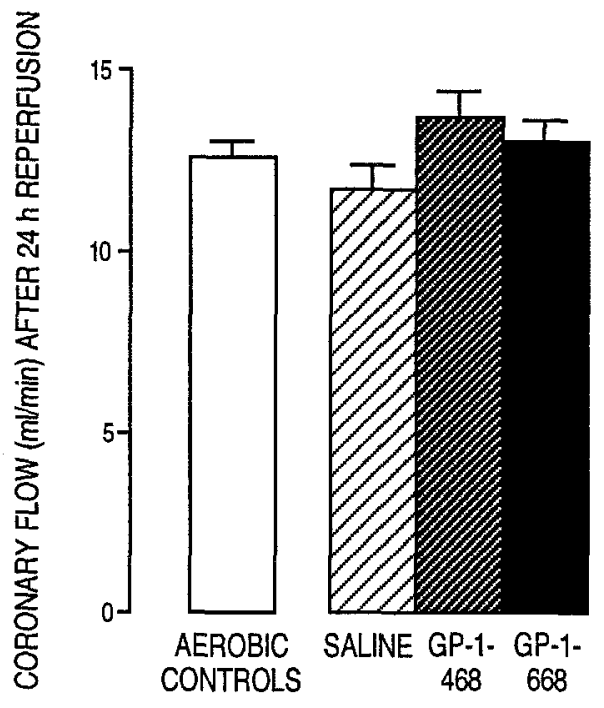

Fig. 4. Coronary flow measured in aerobic, nonischemic control hearts and in hearts subjected to 5 hours of ischemia and 30 minutes (A) or 24 hours (B) of reperfusion, each treated with saline solution, GP-1-468, or GP-1-668 ( $n=8$ per group). The bars indicate the standard error of the mean. ${ }^{*} p<0.05$ when compared with the other groups.

when adenosine triphosphate is catabolized (as during myocardial ischemia). GP-1-668 is a soluble 5 -monophosphate prodrug, which is metabolized rapidly in vivo (half-life $<1$ minute) to GP-1-343, the active dephosphorylated compound. In vitro studies use GP-1-343, whereas GP-1-668 is administered for in vivo studies. However, in both cases the activity resides with GP-1-343 and thus the two compounds are virtually interchangeable. GP-1-468 and GP-1-343 are sevenfold to tenfold more effective than acadesine at inhibiting the use of radiolabelled extracellular adenosine by cultured endothelial cells (J. Barankiewicz, unpublished observation, 1992). The mechanism by which acadesine, GP-1468, and GP-1-343 regulate adenosine levels is currently the subject of intense investigation. Like the parent molecule, GP-1-468 and GP-1-343 improve postischemic contractile function in the isolated buffer-perfused rat heart. This effect can be prevented by the coadministration of the adenosine receptor antagonist 8-SPT. Receptor binding studies indicate that these compounds have extremely low affinity for adenosine $A_{1}$ and $A_{2}$ receptors with less than $20 \%$ binding at $10^{-3} \mathrm{~mol} / \mathrm{L}$ (A. Foster, unpublished observation, 1992), thereby supporting the notion that their adenosinergic activity is mediated by endogenous adenosine rather than a direct effect on adenosine receptors.
Potential advantages of GP-1-468 and GP-1-668 over acadesine and the reason for the search for new acadesine analogs. The clinical efficacy of acadesine in reducing perioperative myocardial injury and other adverse cardiovascular outcomes in patients undergoing coronary artery bypass grafting indicates that adenosine-regulating agents represent a new class of therapeutic agent for the treatment of ischemic heart disease. Consequently, it is appropriate to develop a series of agents with differing profiles and, consequently, differing applications for the treatment of stable angina, unstable angina, acute myocardial infarction, and other ischemic syndromes. For example, acadesine has limited oral bioavailability $(<10 \%)$ and a short half-life; hence its use to treat chronic ischemic conditions in this delivery form might be limited. GP-1-468 was developed as an orally active adenosine-regulating agent. It has an oral bioavailability in dogs of about $30 \%$ and an extended half-life (from 30 minutes to approximately 8 hours). Furthermore, GP-1-468 and GP-1-668 are more potent and more efficacious than acadesine. For example, in the isolated heart subjected to ischemia and reperfusion, acadesine is optimal at a concentration of $20 \mu \mathrm{mol} / \mathrm{L}$, which results in an improved functional recovery. ${ }^{9,11}$ In the same preparation both GP-1-468 and GP-1-343 are optimal at $5 \mu \mathrm{mol} / \mathrm{L}^{12,14}$ This enhanced benefit 

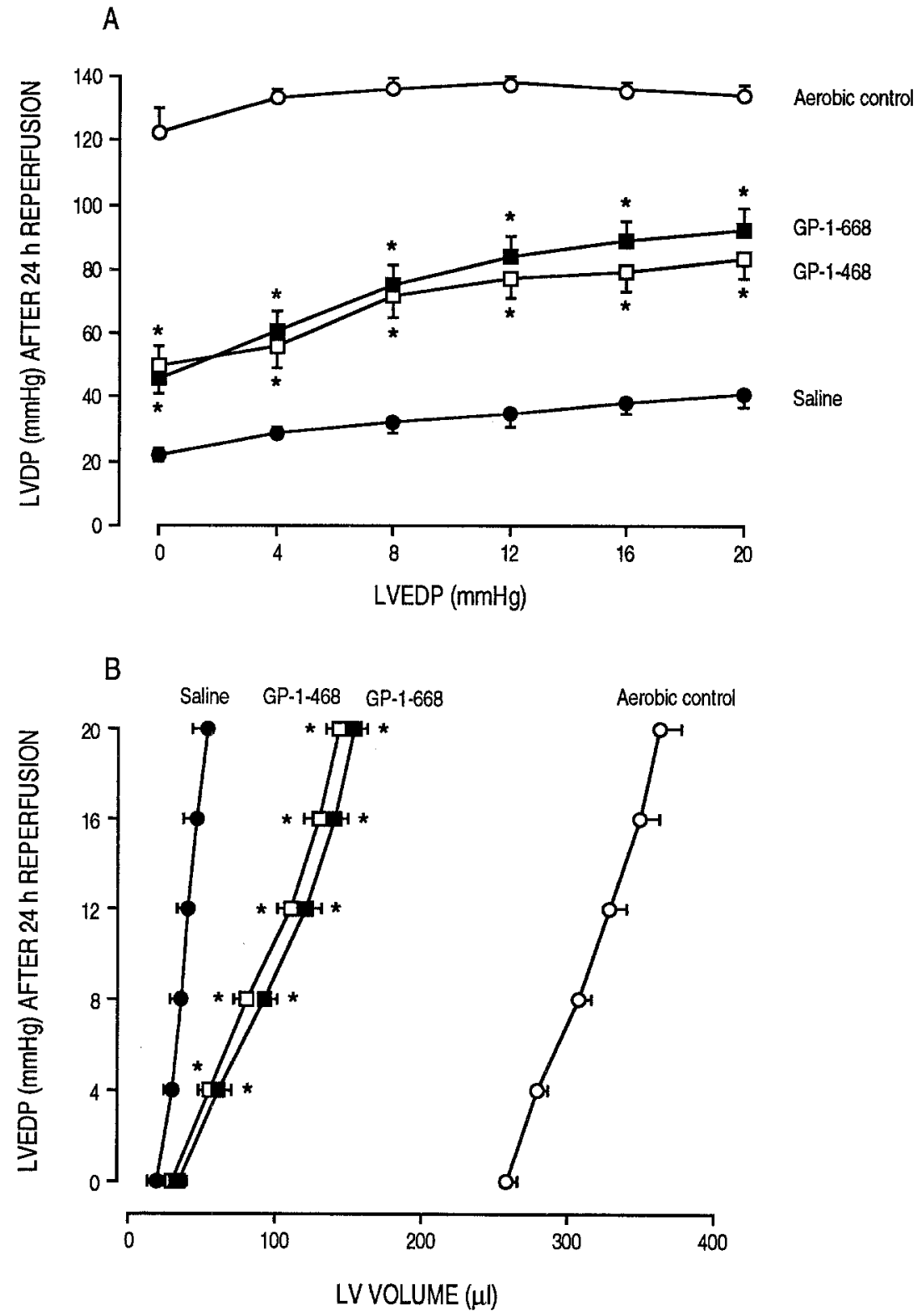

Fig. 5. Systolic (A) and diastolic (B) contractile function curves obtained in aerobic, nonischemic control hearts and in hearts reperfused for 24 hours after 5 hours of ischemia, each treated with saline solution, GP-1-468, or GP-1-668. LVEDP was increased stepwise from 0 to 4, 8, 12, 16, and $20 \mathrm{~mm} \mathrm{Hg}(n=8$ per group). The bars indicate the standard error of the mean. * $p<0.05$ when compared with saline-treated controls.

is consistent with their augmented adenosine-regulating activity. Likewise, in the current experiments, doses of the analogs that were lower than acadesine doses were required to elicit protection.

Possible mechanisms of cardioprotection by GP-1-468 and GP-1-668. In the present study the protective effects of both analogs on contractility and vascular function were unrelated to the conser- vation of high-energy phosphate metabolites at the end of ischemia; however, they were associated with a greater accumulation of tissue adenosine. Certainly, this finding is consistent with adenosine being the mediator of the protection, a conclusion supported by studies in which 8-SPT blocked the improvement in functional recovery that was elicited by the two analogs in an isolated heart preparation. 
Moreover, adenosine exerts a variety of beneficial effects on the myocyte and endothelial cells ${ }^{21}$ and also on leukocytes ${ }^{21-23}$ and platelets. ${ }^{24}$ Indeed, the mechanisms by which adenosine alleviates ischemiareperfusion injury have not been defined but are suggested to include the following: (1) stimulation of glycolytic flux, ${ }^{25}(2)$ inhibition of lipolysis, which thereby stabilizes cellular membranes and decreases intracellular lactate and subsequent acidosis; ${ }^{26}$ (3) an antiadrenergic effect that reduces the release of norepinephrine from sympathetic nerve endings, ${ }^{27}$ and (4) an ability to inhibit superoxide generation by neutrophils, ${ }^{21,22}$ neutrophil plugging, ${ }^{23}$ and platelet aggregation. ${ }^{24}$ The similarity of protection afforded by both GP-1-468 and GP-1-668 suggests that their adenosine-regulating activity is primarily responsible for the benefits observed, and their secondary pharmacologic characteristics, such as inhibition of lipid peroxidation by GP-1-468, do not contribute substantially in this model. These results also imply that the inhibition of platelet activation by GP-1-668 but not by GP-1-468 is not a contributory factor to the protection of the transplanted heart.

In contrast to the forgoing, it should be noted that, using an identical experimental preparation, $\mathrm{we}^{28}$ have shown that the administration of adenosine itself at the end of an ischemic period results in only a short-term benefit that is lost by 24 hours of reperfusion. Because the two analogs induced a sustained protective effect, a factor or factors other than adenosine could also contribute. Alternatively, the timing of drug administration may also be important, and a protocol that involves a pretreatment period could help to precondition the heart from any subsequent injury. We have not fully explored the issues related to the timing of drug administration, but the protocol of the present study matched that of our earlier study ${ }^{10}$ to permit comparison of the analogs to the parent acadesine.

Clinical relevance and applicability. The ability of the two acadesine analogs to improve the functional recovery after a period of ischemia might find important clinical applications in cases in which the onset and duration of ischemia are known. In this connection, routine cardiac surgery and cardiac transplantation are areas in which these drugs may be used to reduce the morbidity and mortality associated with impaired cardiac function.

The potential clinical application of acadesine has been investigated in three placebo-controlled, double-blind, multicenter studies that have evaluated the efficacy of acadesine in reducing cardiovas- cular complications in patients undergoing coronary bypass grafting. ${ }^{20,29-31}$ In all the studies, the administration of acadesine tended to decrease, and in some instances, such as the incidence of perioperative myocardial infarction and stroke, it achieved a level of statistical significance. A fourth multicenter study investigating the efficacy of acadesine against ischemic events in patients undergoing coronary bypass grafting was recently completed in the United States during 1994. This study involved more than 2500 patients, and it showed that although acadesine tended to reduce the incidence of perioperative cardiovascular events, this difference did not achieve statistical significance. The complete results have yet to be presented or published. It might be argued that in these studies end points such as myocardial infarction, cardiac death, and stroke were used rather than other functional and/or structural indexes as in this current study. Independently of the controversy on appropriate indexes used for the assessment of efficacy of the drug, it should be emphasized that substantial experimental and clinical data support a beneficial effect of adenosine-regulating agents against injury sustained during ischemia and reperfusion ${ }^{31}$ and that the search for agents with pharmacodynamic properties and efficacy greater than those of acadesine should be continued.

\section{Conclusions}

The two acadesine analogs, GP-1-468 and GP-1668 , accelerate the rate and extent of postischemic recovery and afford sustained protection of cardiac function against injury during ischemia and reperfusion. These effects were associated with an increase of tissue content of adenosine during ischemia but they appeared to be independent of the status of the high-energy metabolism.

The statistical advice of Mr. N. Taub is gratefully acknowledged.

\section{REFERENCES}

1. Gruber HE, Hoffer ME, McAllester DR, et al. Increased adenosine concentration in blood from ischemic myocardium by AICA riboside. Circulation 1989;80:1400-11.

2. Young MA, Mullane KM. Progressive cardiac dysfunction with repeated pacing-induced ischemia: protection by AICA-riboside. Am J Physiol 1991;261: H1570-7.

3. Cronstein BN, Eberle MA, Gruber HE, Levin RI. Methotrexate inhibits neutrophil function by stimulat- 
ing adenosine release from connective tissue cells. Proc Natl Acad Sci U S A 1991;88:2441-5.

4. Bullough DA, Zhang C, Mullane KM. Acadesine (AICA riboside) inhibits platelet aggregation in human whole blood [Abstract]. Int J Purine Pyrimidine Res 1991;2(Suppl 1):66.

5. Henry CA, Young $M$, Zhang $C$, et al. Adenosine release from red cells mediates inhibition of platelet aggregation by acadesine and delays post-thrombolytic reocclusion in dogs. Circulation 1991;84(Suppl): II 246 .

6. Bullough DA, Fox M, Potter S, et al. AICA riboside protects myocardial tissue from reperfusion injury and oxidant induced damage. FASEB J 1991;5:A1436.

7. Vincent MF, Bontemps F, Van Den Berghe G. Inhibition of glycolysis by 5-amino-24-imidazolecarboxamide riboside in isolated rat hepatocytes. Biochem $\mathrm{J}$ 1992;281:267-72.

8. Tsuchida A, Liu GS, Mullane K, Downey JM. Acadesine lowers temporal threshold for the myocardial infarct size limiting effect of preconditioning. Cardiovasc Res 1993;27:116-20.

9. Galiñanes M, Mullane KM, Bullough D, Hearse DJ. Acadesine and myocardial protection: studies of time of administration and dose-response relations in the rat. Circulation 1992;86:598-608.

10. Galiñanes M, Bullough D, Mullane KM, Hearse DJ. Sustained protection by acadesine against ischemiaand reperfusion-induced injury: studies in the transplanted rat heart. Circulation 1992;86:589-97.

11. Bullough DA, Fox MH, Mullane KM. Acadesine regulates adenosine to improve post-ischemic function in the isolated heart. J Mol Cell Cardiol 1992; 24(Suppl III):S6.

12. Magill MJ, Fox MH, Young MA, Mullane KM, Bullough DA. Adenosine mediates the cardioprotective actions of GP-1-468 in the isolated heart. FASEB J 1993;7:A119.

13. Pan W, Mullane KM, Young MA. Anti-ischemic activity of the novel adenosine regulating agent, GP-1-468, in a canine model of stable angina. FASEB J 1993;7:A119.

14. Bullough D, Drake L, Zhang C, Magill M, Mullane K. Dual anti-ischemic activity and inhibition of LDL oxidation represents two independent mechanisms of protection with GP-1-468. FASEB J 1994;8:A635.

15. Montag A, Metzner K, Kopcho J, Mullane K, Young M. Adenosine-mediated antithrombotic effects of the novel adenosine-regulating agent GP-1-668. Pharmacologist 1993;35:180.

16. Montag A, Pan W, Mullane KM, Young MA. GP-1668 enhances thrombolysis in combination with aspirin in the rabbit carotid artery. FASEB J 1994;8:A268.

17. Krebs HA, ${ }^{*}$ Henseleit $K$. Untersuchungen über die Harnstoffbildung im Tierkörper. Hoppe Seylers Z Physiol Chem 1932;210:33-66.
18. Langendorff $O$. Untersuchungen am uberlebenden Saugethierherzen. Pflugers Arch 1895;61:291-332.

19. Holliss DG, Humphrey SM, Morrison MA, Seelye RN. Reverse phase HPLC for rapid, comprehensive measurements of nucleotides, nucleosides and bases of the myocardial adenine pool. Anal Letters 1984; 17(B18):2047-65.

20. Leung J, Stanley T, Mathew $\mathrm{J}$, et al. An initial multicenter, randomized controlled trial on the safety and efficacy of acadesine in patients undergoing coronary artery bypass graft surgery. Anesth Analg 1994; 778:420-34.

21. Cronstein BN, Levin RI, Belanoff $\mathbf{J}$, Weissman G, Hirschhorn R. Adenosine: an endogenous inhibitor of neutrophil-mediated injury to endothelial cells. J Clin Invest 1986;78:760-70.

22. Engler R. Consequences of activation and adenosinemediated inhibition of granulocytes during myocardial ischemia. Fed Proc 1987;46:2407-12.

23. Grisham MB, Hernandez LA, Granger DN. Adenosine inhibits ischemia-reperfusion-induced leukocyte adherence and extravasation. Am J Physiol 1989;257: H1334-9.

24. Gerlach E, Becker BF, Nees S. Formation of adenosine by vascular endothelium: a homeostatic and antithrombogenic mechanism? In: Grelach E, Becker BF, eds. Topics and perspectives in adenosine research. Berlin: Springer, 1987:309-20.

25. Wyatt DA, Edmunds MC, Rubio R, Berne RM, Lasley RD, Mentzer RM Jr. Adenosine stimulates glycolytic flux in isolated perfused rat hearts by A1adenosine receptors. Am J Physiol 1989;257:H1952-7.

26. Fredholm BB. Methods used to study the involvement of adenosine in the regulation of lipolysis. In: Paton DM, ed. Methods in pharmacology. New York: Plenum, 1985:337-57.

27. Fredholm BB, Dunwiddie TW. How does adenosine inhibit transmitter release? Trends Pharmacol Sci 1988;9:130-4.

28. Galiñanes M, Hearse DJ. Exogenous adenosine accelerates recovery of cardiac function and improves coronary flow after long-term hypothermic storage and transplantation. J Thorac Cardiovasc Surg 1992;104:151-8.

29. Menasché P. Multinational study of the effect of acadesine on myocardial infarction and adverse cardiovascular outcomes associated with CABG surgery. Eur Heart J 1993;14:425.

30. Mangano DT. Multicenter study of acadesine for the prevention of myocardial infarction and other adverse cardiovascular outcomes associated with coronary artery bypass graft surgery. Eur Heart $\mathbf{J}$ 1994;15:66.

31. Mullane K, Bullough D, Shapiro D. From academic vision to clinical reality: a case study of acadesine. Trends Cardiovasc Med 1993;3:227-34. 